\title{
Patients' usability of seven most used dry-powder inhalers in COPD
}

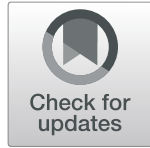

Roberto W. Dal Negro ${ }^{1 *}$ (D), Paola Turco ${ }^{2}$ and Massimiliano Povero ${ }^{3}$

\begin{abstract}
Introduction: Inhalation devices affect both the effectiveness and the therapeutic outcomes in persistent airway obstruction, and the effects are largely independent of the drug(s) assumed. Usability is a complex and comprehensive indicator of inhalation devices' performance. The Global Usability Score (GUS) Questionnaire is an investigational tool designed to assess objectively the patients'-related and unrelated domains of devices' usability.

Methods: The GUS questionnaire was administered to all consecutive COPD patients referring for three months to the Lung Unit of CEMS Specialist Centre (Verona, Italy). The usability of seven Dry Powder Inhalers (DPIs) indicated as appropriate in COPD was tested and compared: Breezhaler, Diskus, Ellipta, Genuair, Nexthaler, Spiromax, and Turbohaler. Patients were divided in two groups, checked separately, according to their DPls previous experience. A Bayesian Indirect Comparison (IC) model was built to assess "global usability" ranking.
\end{abstract}

Results: A total of 103 patients were investigated: 74 patients already instructed in DPI use and 29 naive to DPIs. IC analysis proved Ellipta as the device characterized by the highest usability, while Breezhaler the device with the lowest usability in both groups of COPD patients (both with probability > 90\%). Moreover, Turbohaler ranked second according to the Bayesian pooling, followed by Diskus, Spiromax, Nexthaler, and Genuair in patients already instructed in DPI use, while the ranking order was not as much well defined in naïve patients, likely due to their too small sample.

Conclusions: Usability is a multifaceted indicator that contributes to assess the factual DPIs' convenience in real life. DPIs are characterized by different levels of real-life usability, which can be checked, compared and ranked by means of the GUS score.

Keywords: Dry powder inhalers, COPD, Global usability score, Inhalation therapy, Usability

\section{Introduction}

Effective actions oriented to increasing both the awareness and the empowerment of patients suffering from Chronic Obstructive Pulmonary Disease (COPD) who need long-term inhalation therapy raised powerfully during the last decade, being the concept of adherence to treatment, together to that of personalized therapy, strongly supported [1].

Due to the continuous growing in the number of inhalation devices of different technologies, increasing evidence proved that patients are unable to use all inhalers equally well, and the training with inhalers should have consequently been regarded as a priority

\footnotetext{
* Correspondence: robertodalnegro@gmail.com

${ }^{1}$ National Centre for Respiratory Pharmacoeconomics and

Pharmacoepidemiology, Verona, Italy

Full list of author information is available at the end of the article
}

challenge $[1,2]$. On the other hand, a substantial bulk of data showed that inhalers represent a critical factor per sé as they may affect the therapeutic outcomes substantially, even independently of the molecules used [3-6].

Several aspects of patients' adherence to inhalation treatments had been extensively investigated. In particular, the determinants of patients' insufficient adherence were mostly related to those of patients' preference, or acceptance, or satisfaction by the majority of Authors [7-13]. Patients' subjectivity and empowerment were consequently highly valued from this point of view, even if the correspondence between patients' beliefs, DPIs' performances, and their effective usability had been investigated with specific instruments only in few studies in real-life [1, 14-19].

(c) The Author(s). 2019 Open Access This article is distributed under the terms of the Creative Commons Attribution 4.0 International License (http://creativecommons.org/licenses/by/4.0/), which permits unrestricted use, distribution, and 
The Global Usability Score (GUS) Questionnaire is a comprehensive and anonymous operational instrument specifically developed for assessing and compare objectively the global usability of inhalation devices [20]. The GUS questionnaire was preferred to other instruments available in the literature $[11,16,17,19]$ because it allows the assessment of a much wider range of domains, thus resulting in a more comprehensive usable score.

\section{Aim}

The aim of the study was to assess and compare the usability of the seven most used Dry Powder Inhalers (DPIs) in DPI naïve and in educated COPD patients.

\section{Methods}

In order to investigate the usability of different DPIs, the GUS questionnaire [20] was administered to all consecutive COPD patients referring to the CEMS Specialist Centre (Verona-Italy) during the trimester October-December 2017. The GUS questionnaire is an anonymous operational instrument specifically developed for assessing and comparing objectively the usability of different inhalation devices simultaneously. This questionnaire was chosen because it allows the investigation of a wider range of factors affecting usability, and takes in the right value the nurse's controlled assessment of patients' inhalation procedures (see the Additional file 1). In order to avoid any influence of the subjects responses, the values corresponding to subjects' responses to each item of the questionnaire (see Additional file 1) were obviously not reported in the version of Questionnaire distributed to subjects (otherwise their responses would be influenced), being the final GUS calculated by the steering committee only once the questionnaire had been filled definitively.

DPI experienced were enrolled together to naive subjects just in order to investigate whether or not DPIs' usability can be affected by previous subjects' experiences with DPIs. Obviously, naïve subjects, even though having experienced inhalation therapies in their past, had never experienced any DPI previously.

The seven most used DPIs officially indicated in COPD were checked: Breezhaler, Diskus, Ellipta, Genuair, Nexthaler, Spiromax, and Turbohaler. Each patient was asked to evaluate up to four devices (randomly grouped) in the same session.

Two nurses, interchangeable because equally expert and motivated in educational programs, and familiar with the technical and the psychological aspects of the GUS Questionnaire, were specifically dedicated to patients' interviews, and to supervise, check, assess, and validate all patients' procedures for inhalation. The study consisted in four different steps:

Step 1 - The attending nurse investigated the basic knowledge of each patient in DPI use.

Step 2 - The nurse displayed the correct functioning of each DPI to each patient (already instructed or naïve) in random order. All explanations were provided according to a fixed sequence of sentences, being their duration previously standardized. Patients were then requested to declare their preference at glance and to specify the reason for their choice. All information collected during this phase were reported in the \# 1 box of the Assessing Track (AT) section of the questionnaire (see Additional file 1).

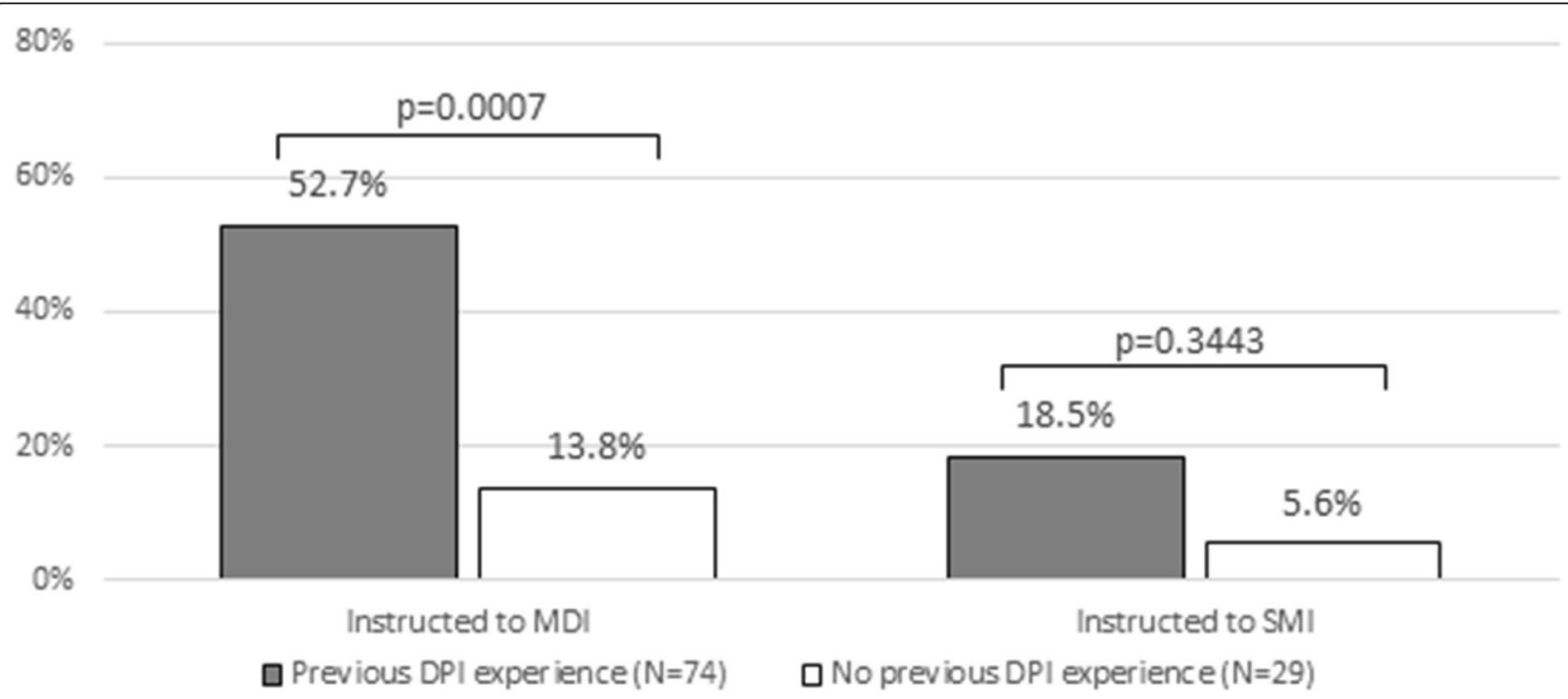

Fig. 1 Previous experience with MDI and SMI: comparison between DPI experienced patients and DPI naïve patients. DPI: dry-powder inhalers; MDI: metered dose inhalers; SMl: soft mist inhalers 
Step 3 - Patients were then requested to prepare the actuation of each device by themselves, while the nurse was monitoring and assessing the patients' technicality. Their critical issues had to be valued; the number of attempts needed for actuating the device properly counted, and the overall time spent measured. Data on patients' beliefs, the reasons of their choices, and quantitative data of nurse's direct measurements were reported in boxes \# 2-4 of the GUS questionnaire (see Additional file 1).

Step 4 - Finally, data from other ten closed questions related to further subjects' personal beliefs attaining to the acceptance and the preference of each device, were collected and reported in box \# 5 (see Additional file 1).

At the end of each box of the Assessing Track, a subscore is calculated. At the end of the whole questionnaire, the final Global Usability Score is easily obtained by summing-up all the sub-scores calculated for each DPI. The GUS final score ranges 0-50 points; higher the value of the score for each DPI, higher the corresponding usability will be.

\section{Ethics}

The study was approved by the Ethical and Scientific Commission of the National Centre for Respiratory Pharmacoeconomics and Pharmacoepidemiology during the session of January $4^{\text {th }}, 2016$ (\# RD 011/G01/16).

Only data collected from patients who gave their informed consent to the investigation and to the possible use of information for scientific purposes were used for the present study.

\section{Statistics}

Patients' characteristics were summarized as percentage for dichotomous and categorical variables, or as mean $( \pm$ standard deviation) for continuous data. Difference in baseline characteristics among patients who tested the different sequences of devices were tested by means of chi-squared test for dichotomous/categorical or by ANOVA test for continuous variables.

All pairwise comparisons between the seven DPIs were merged using a Bayesian Indirect Comparison (IC) model [21]. Generally, IC models are used for pooling quantitative results from multiple studies and for assessing the effect between two or more treatments; in our context, "multiple studies" meant groups 1, 2, 3, and "treatments" means devices. This approach is particularly advantageous because all devices under comparison are incorporated into a single model even if they are not compared in the same questionnaire. Furthermore, the Bayesian technique enables rank ordering of each device (i.e. the probability associated to each one being the $1^{\text {st }}$, $2^{\text {nd }}, 3^{\text {rd }}, \ldots$ best device) hence it results in a "global usability" ranking. Both fixed-effect (FE) and random-effect (RE) model were run. A FE analysis assumes that each individual generates an estimate of the same effect $d$ (the preference of one device rather than another, in this case), subjected to sampling error; in a RE model, each individual $i$ provides an estimate of the device effect $\delta_{i}$, which is not equal but similar to the real effect that is each effect $\delta_{i}$ comes from a normal distribution with mean $d$ and variance $\sigma^{2}$ representing the variability between respondents. The relative goodness of fit of the models was assessed by using the Deviance Information Criterion (DIC). Both FE and RE models were developed and the one associated to the lowest DIC was selected [22], with a difference of at least three points in DIC [23]. The model with the smallest DIC is the model with the best compromise between adequacy and complexity. Estimated GUS score for each device was presented as mean and 95\% credibility interval ( $\mathrm{CrI})$.

Statistical analyses were performed with $\mathrm{R}$ statistical software version 3.1.2 [24], a $p$ lower than 0.05 is considered to indicate evidence of differences in the evaluated variables. The Bayesian IC model was developed by using the software package WinBUGS 1.4.3 [25].

\section{Results}

A total of 103 consecutive COPD patients were enrolled during ambulatory visits. The main characteristics of the whole sample were: males $=61.6 \%$; mean age $=66.8$ years \pm $8.2 \mathrm{sd}$; mean BODE Index $=4.3 \pm 2.7 \mathrm{sd}$; mean $\mathrm{FEV}_{1}(\mathrm{~L})=$ $1.48 \mathrm{~L} \pm 0.51 \mathrm{sd} ;$ mean $\mathrm{FEV}_{1} \%$ pred. $=56.3 \% \pm 16.2 \mathrm{sd}$ mean $\%$ reversibility from baseline $=5.2 \pm 5,2 \mathrm{sd}$; active smokers were $23.3 \%(n=24)$, while former smokers $64.1 \%$ $(n=66)$, and never smokers $12.6 \%(n=13)$. Their presumed mean COPD duration was 9.8 years $\pm 7.9 \mathrm{sd}$ and their mean value of Charlson Comorbidity Index was $3.2 \pm 1.7 \mathrm{sd}$. Their mean rate of COPD exacerbations was $1.6 \pm 1.4 \mathrm{sd}$ and the mean rate of hospital admissions was $0.6 \pm 0.7$ during the previous twelve months.

A proportion of $28 \%(n=29)$ were subjects naïve to DPIs (such as, they had never received a DPI prescription previously) while $72 \%$ of patients $(n=74)$ had already experienced DPIs (Fig. 1). In particular, the latter subgroup of subjects were prescribed and experienced almost all DPIs available on the market during the last decade for different periods.

Patients were divided in 3 groups, evenly distributed according the DPIs tested: Group 1, 36 patients who tested Breezhaler, Spiromax, Nexthaler, and Ellipta; Group 2, 37 patients who tested Breezhaler, Spiromax, Diskus, and Turbohaler, and Group 3, 30 patients who tested Breezhaler and Genuair. Baseline patients' characteristics are reported in Table 1 . Their age, sex and education distribution were similar among the three groups; 
Table 1 General characteristics of patients who evaluated devices using the Global Usability Score questionnaire

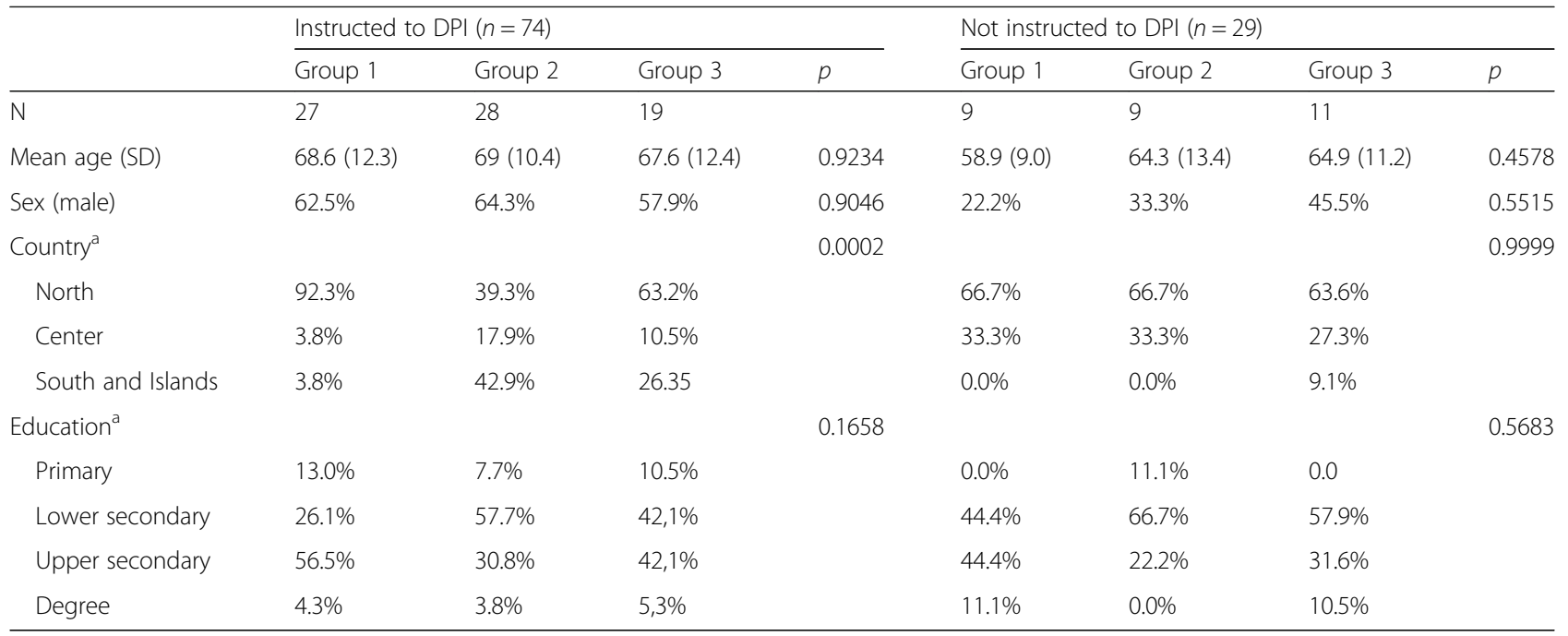

Group1 tested Breezhaler, Spiromax, Nexthaler, and Ellipta; Group 2 tested Breezhaler, Spiromax, Diskus, and Turbohaler; Group 3 tested Breezhaler and Genuair; DPI dry powder inhalers, SD standard deviation

${ }^{a}$ Information about country and education are reported also for Group 3, even though available only a few patients who answered those questions

only their geographical distribution was different in patients previously experienced in DPIs use.

As expected, experienced patients were also more instructed in the use of metered dose inhalers (MDI) than naïve patients $(52.7 \%$ vs $13.8 \%$, delta $=38.9,95 \% \mathrm{CI}$ $19.6-58.2 \%, p=0.0007)$; the same trend was also observed for those previously experienced in the use of soft mist inhalers (SMI), even if the difference did not reach the statistical significance in this case $(18.5 \%$ vs $5.6 \%$, delta $=12.9,95 \%$ CI $-5.6-31.5 \%, p=0.3443$ ).

Evidence network resulted from the 103 questionnaires is illustrated in Fig. 2. Ellipta, Nexthaler, and Breezhaler are directly compared only in group 1; Turbohaler, Diskus, and Spiromax are directly compared only in group 2; Breezhaler and Spiromax are directly compared both in group 1 and 2 while Genuair is compared with Breezhaler only in group 3.

In running our Bayesian analysis, the value of DIC was found to be more favorable for the FE model than the RE model, both for the DPI experienced population (DIC $=53.512$ in FE model vs 53.921 in RE model) and for the DPI naïve population (DIC $=58.652$ in FE model vs 58.702 in RE model). As explained in the statistics section, only the results generated by this model are presented since the model with the smallest DIC is the model with the best compromise between adequacy and complexity.

The estimated GUS value for each device considered in the study are reported in Fig. 3. The usability of Ellipta and Breezhaler proved independent of the patient's original level of previous instruction; furthermore, the two devices were characterized by the highest (Breezhaler) and the lowest (Ellipta) GUS score. However, only in the DPI experienced group (Fig. 3-a), the trend in usability proved quite linear from Ellipta (with the highest GUS) to Breezhaler (the lowest GUS). In the naïve group, GUS scores of Turbohaler, Spiromax, Diskus, and Nexthaler resulted very similar and also 95\% CrI were very close (Fig. 3-b).

The histograms of rankings generated by the Bayesian pooling in originally instructed and in naive COPD patients are reported in Fig. 4. The graphs reflect 100,000 iterations and consist of as many histograms as the devices included in the analysis. In each panel, each histogram shows the percent distribution of the simulations across ranks $1^{\text {st }}$ (the greatest GUS) to $7^{\text {th }}$ (the lowest GUS), while the y-axis shows the probability on a 0 to 1 scale. As anticipated by Fig. 3 for the DPI experienced COPD patients, the individual ranking of the 7 devices was straightforward: Ellipta $1^{\text {st }}$ (up to $2^{\text {nd }}$ ), Turbohaler $2^{\text {nd }}\left(1^{\text {st }}\right.$ to $\left.3^{\text {rd }}\right)$, Diskus $3^{\text {rd }}\left(2^{\text {nd }}\right.$ to $\left.5^{\text {th }}\right)$, Spiromax tied with Nexthaler $\left(4^{\text {th }}\right.$ to $\left.6^{\text {th }}\right)$, Genuair $6^{\text {th }}\left(4^{\text {th }}\right.$ to $\left.7^{\text {th }}\right)$, and Breezhaler $7^{\text {th }}\left(6^{\text {th }}\right.$ to $\left.7^{\text {th }}\right)$. In particular, Ellipta had more than $90 \%$ probability to be the first preferred device; Turbohaler had the highest probability to rank $2^{\text {nd }}$ (68\%), but there was also a $23 \%$ to be 3rd. For the naïve population the ranking order did not prove as much definable: even if Ellipta has almost $100 \%$ of probability to be the first and Breezhaler 35 and $64 \%$ of probability to be the $6^{\text {th }}$ or the $7^{\text {th }}$, respectively; the ranking of the other five devices appeared evenly distributed between rank $2^{\text {nd }}$ and rank $6^{\text {th }}$. In particular, Turbohaler, Spiromax, and Diskus were be distinguishable between ranks 2 and 4 .

\section{Discussion}

The choice (and switching) of inhaler devices, in particular of DPIs, is a crucial issue in real-life studies since 


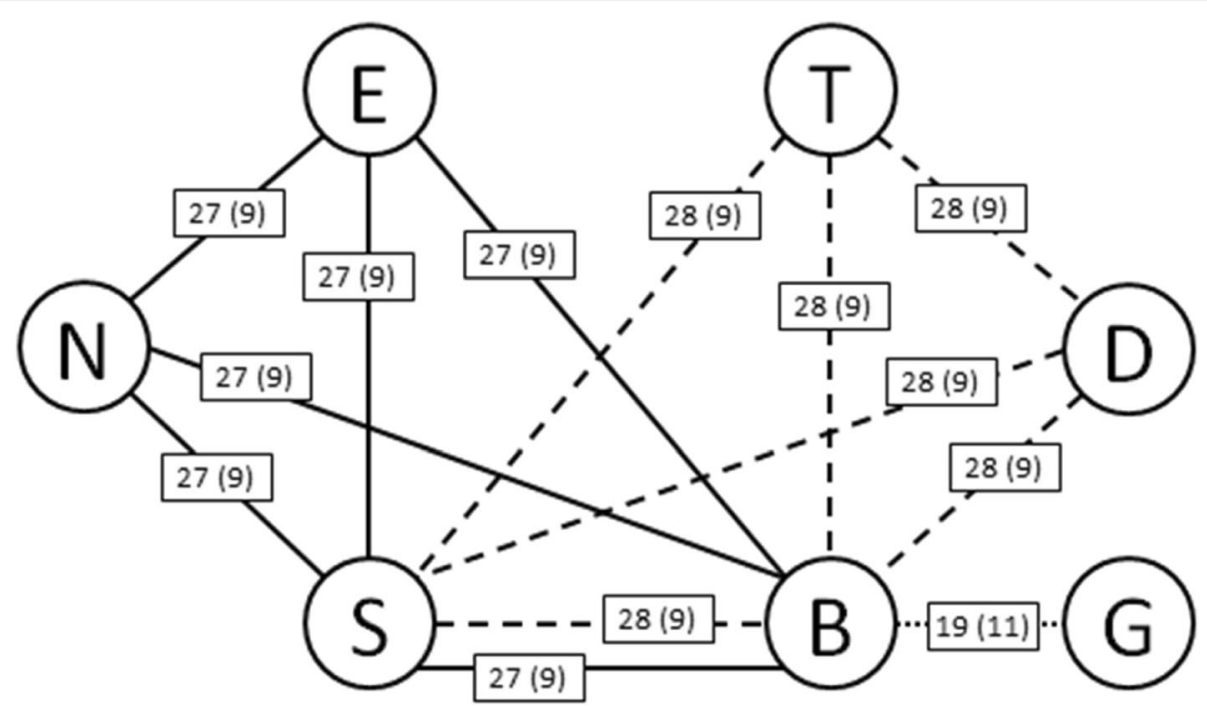

Fig. 2 Evidence network based on patients' comparisons in the three groups, every edge between two nodes is labelled with the number of patients that compared the devices represented with previous experience in the use of DPI (in brackets those without previous experience); solid lines represent comparison in group 1, dotted lines represent comparisons in group 2 and point line represents comparison between Breezhaler and Genuair in group 3 B: Breezhaler; D: Diskus; E: Ellipta; G: Genuair; N: Nexthaler; S: Spiromax; T: Turbohaler

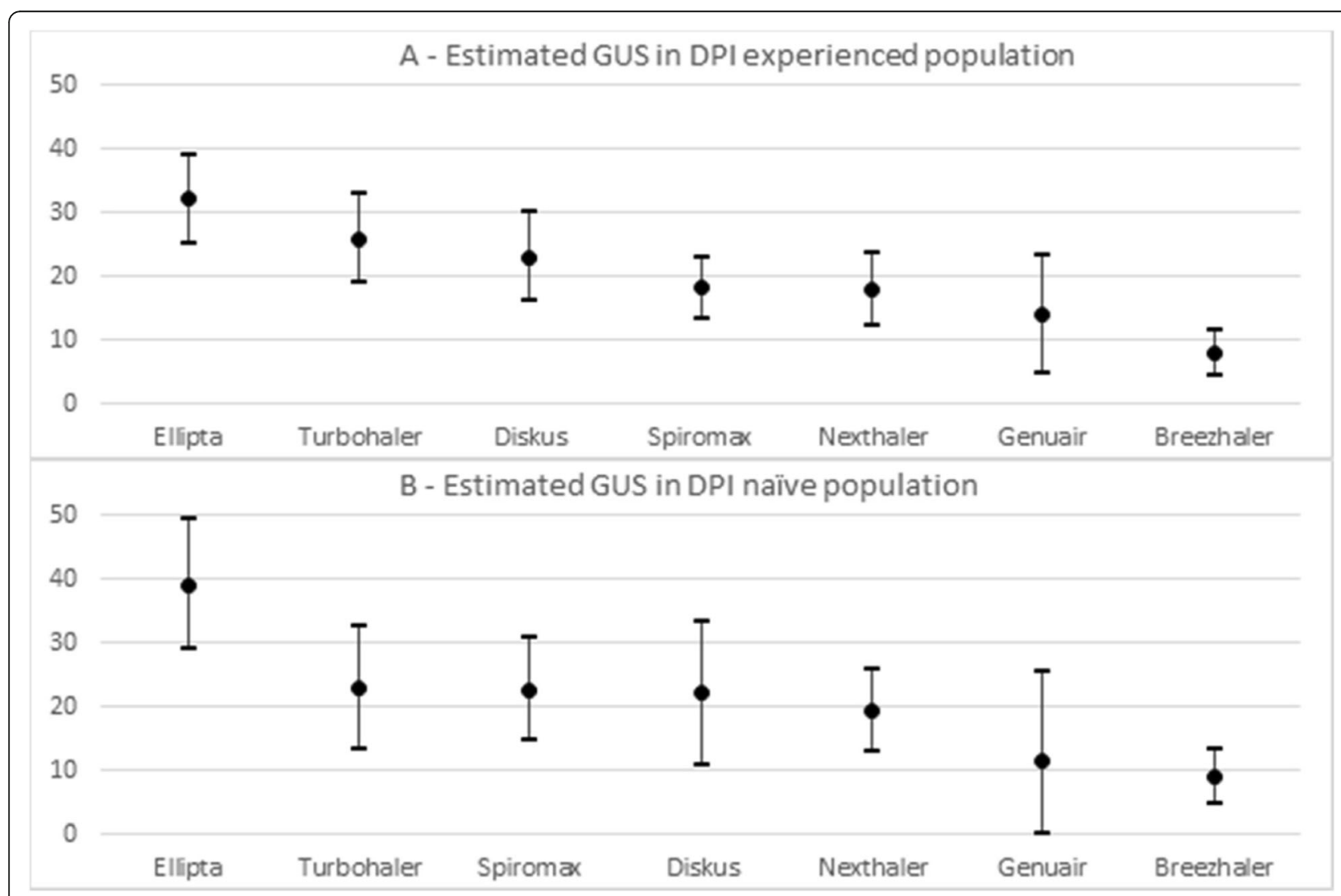

Fig. 3 Ranking of mean GUS score (points) and 95\% Crl (bars) resulting from Bayesian analysis in COPD patients originally already instructed to DPIs (a) and originally naive to DPIs (b). DPI: dry powder inhaler, Crl: credibility interval 


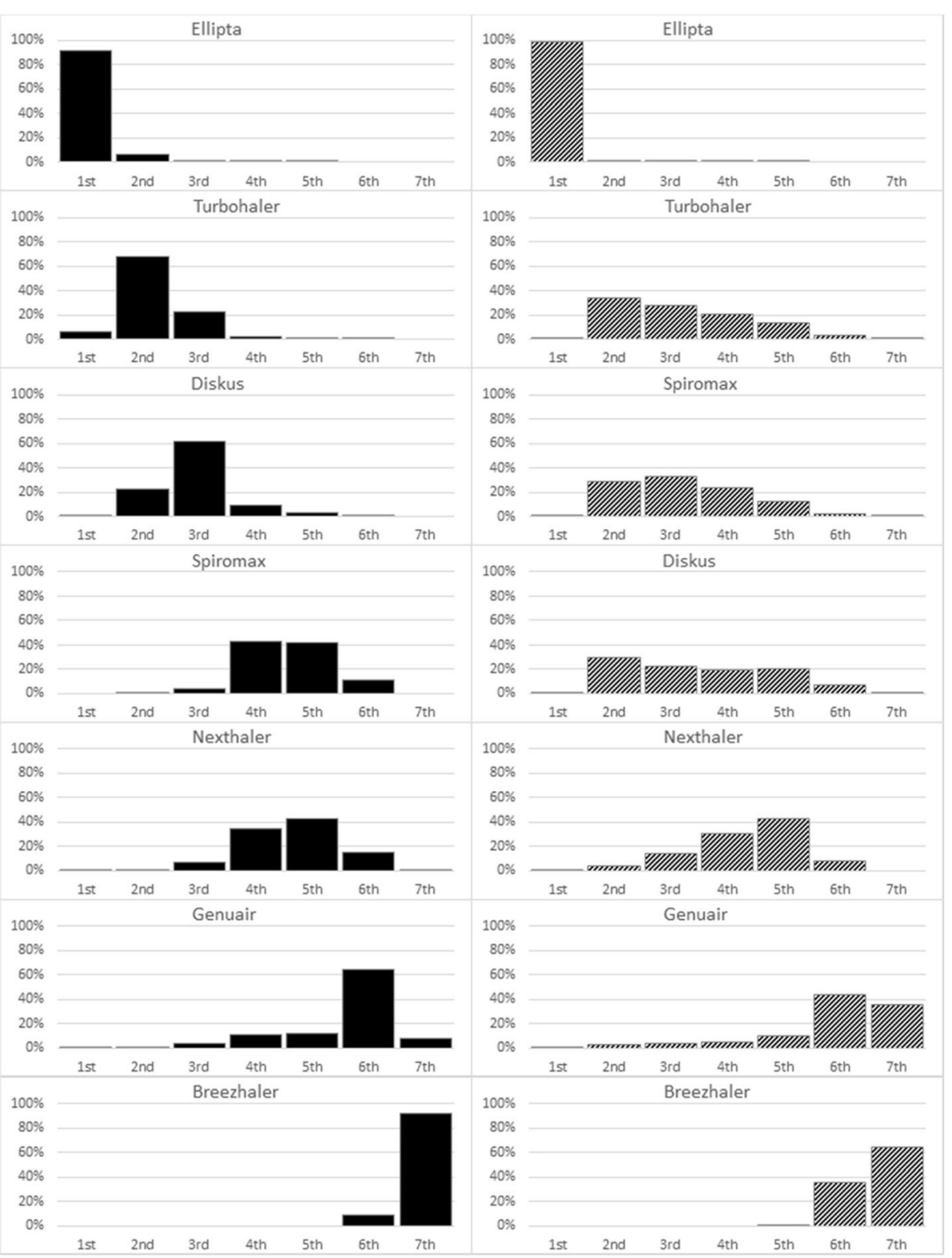

Fig. 4 Histograms of rankings generated by the Bayesian pooling (patients instructed to DPIs on the left, not instructed on the right): the graphs reflect a total of 100,000 iterations and consist of as many histograms as the devices included in the analysis; in each panel, the histogram shows the percent distribution of the simulations across ranks 1 (greater GUS) through 7 (lower GUS) while the $y$-axis shows probability on a 0 to 1 scale

long ago [26]. Systemic reviews on randomized clinical trials did not confirm this evidence because mostly focusing the role of drugs used in the majority of cases. For this reason, patient-centered studies in community setting and/or in unselected samples of subjects had been encouraged in order to provide data much more fitting with real-life conditions and patients behavioral habits [2, 27].

Actually, even if the patients' opinion has been progressively valued much more than in the past, the assessment of aspects which are highly independent of patients' personal viewpoint (such as, the device engineering, the training track and the training costs) should further contribute to provide a much more comprehensive and objective picture of the so called "usability" of inhalation devices.

In real life, DPIs are highly prescribed in Italian COPD patients being their prescription usually independent of their known basic characteristics and technical differences, such as the different number of main actions required for their actuation (7 for Breezhaler, 4 for Ellipta and Turbohaler, and 3 for the remaining devices), 
and their intrinsic resistance, ranging from $0.017 \mathrm{kPa}^{0.5}$ $\mathrm{L} / \mathrm{min}$ to $0.039 \mathrm{kPa}^{0.5} \mathrm{~L} / \mathrm{min}[28,29]$.

Actually, different DPIs confirmed to provide different performances in terms of patterns of lung deposition and inspiratory flow required for an adequate inhalation. On the other hand, both these factors which mainly attain to the intrinsic engineering of the devices $[2,26,30]$, are equally able to affect clinical outcomes, being patients almost completely unaware of their relative value from this point of view [31]. These aspects are recently receiving increasing, even if still insufficient, attention by prescribers. In a multinational survey conducted among primary and secondary care physicians, more than $30 \%$ of them considered the device before considering the respiratory drug to prescribe. Moreover, the vast majority of UK health professionals (87\%) affirmed to be concerned about possible problems arising from therapeutic prescriptions if the inhalation device is not specified, and $86 \%$ of physicians were convinced that DPIs are noninterchangeable and that their unmotivated substitution would have an adverse impact [32].

In several studies (even if mostly consisting of small samples of subjects), the criteria for DPIs preference have been usually related to factors which are strictly dependent of patients' characteristics, beliefs, and subjectivity, such as: their age, visual acuity, hand strength, coordination, cognition, psychological profile, socio-economic status, and educational level. As a consequence, satisfaction, or intuitivity, or willingness to use, or preference "at glance", or dexterity, or ease-of-use, or acceptance were from time to time the indices used for assessing and comparing different DPIs [14, 28, 33, 34].

In the last decade, the term "usability" appeared in the literature, but "usability" is ever more frequently used as a synonymous of "ease of use", even if "usability", per sé, encases a more complex and multifaceted concept, which depend of several determinants from different domains.

In our opinion, "Usability" should be regarded as a much more comprehensive parameter and its effective value results from the weighted mix of subjective (namely, intuitivity, satisfaction, willingness to use, preference "at glance", dexterity, ease-of-use, acceptance, etc.) and objective (such as, those independent of patients' convincement and beliefs, cost included) determinants, all contributing to balance the role of different factors affecting the overall DPIs performance and convenience in real life. To point out that the cost related to DPIs use should also be included among the decision criteria of usability, even if it occurred episodically and usually only related to the cost reimbursement $[6,35]$.

The existence of different domains affecting DPIs usability is clearly confirmed in the present investigation, which was founded on data collected by means of the multidimensional GUS Questionnaire. To pinpoint that also the patient-dependent criteria of choice (namely, preference and ease-of-use, etc.) were carefully assessed (before instruction) and compared (after instruction) by the expert nurses who provided specific scores in order to check and measure the efficacy of the training track with each DPI.

To emphasize that no DPI achieved the theoretical GUS top score of 50 points, thus confirming that the "ideal DPI" is not still available and that, even if well performing, all presently available DPIs are affected by some critical aspects.

Nevertheless, some relevant differences among the seven DPIs used in the present study clearly came out in terms of their usability and, consequently, of educational actions to deliver for boosting their proper utilization. In particular, Ellipta and Breezhaler proved equally independent of patient's original level of instruction, even if they were characterized by dramatically different GUS scores (such as, the highest and the lowest, respectively). Actually, this dramatic difference in GUS value may be likely suggested as due to the fact that, differently from all other six DPIs which are multi-dose inhalers, Breezhaler is a single-dose inhaler characterized by a very low intrinsic resistance which requires a very high subject's inspiratory flow for achieving an effective drug inhalation, and several manoeuvres for its proper actution.

All the other remaining five devices seem to be influenced by a previous DPIs' experience and their ranking proves very clear according to the GUS score: Turbohaler shows almost $70 \%$ of probability to be the $2^{\text {nd }}$; Diskus has $62 \%$ probability to be the $3^{\text {rd }}$; both Spiromax and Nexthaler have $80 \%$ probability to be the $4^{\text {th }}$, and Genuair has $65 \%$ probability to be the $6^{\text {th }}$.

On the other hand, the corresponding trend assessed in naïve COPD subjects does not result as much clear since Turbohaler, Spiromax, Diskus, and Nexthaler showed a probability of $12-34 \%$ to rank as the $2^{\text {nd }}$ up to the $5^{\text {th }}$ most usable device, followed by Genuair ranking $6^{\text {th }}$ or $7^{\text {th }}$ (with a probability of 44 and $35 \%$, respectively), and finally Breezhaler ranking $7^{\text {th }}$ with a probability of $64 \%$. This less defined trend was likely due to the small number of naïve patients evaluated ( 9 patients in both group 1 and 2, and 11 in group 3) which contributes to increase uncertainty in the analysis; in fact, the 95\% CrI presented in Fig. 3-b are larger than those presented in Fig. 3-a.

Moreover, Ellipta, Spiromax, Turbohaler, and Diskus were the DPIs needing the lowest time to spend for achieving the patient's autonomy and the quickest to learn. Once again, even if the expert nursing of inhalation procedures represents a crucial aspect with all DPIs $[8,29,36]$, a careful educational training is mandatory with some DPIs, which are characterized by lower usability scores. 
This evidence is further confirming and stressing the original concept that subjects are unable to use all inhalers equally well $[1,2]$, and that usability consists in and depends of a much more complex set of determinants than simple patients' perceptions. In particular, each single domain is not able to assess per sé the usability of a DPI, differently from the GUS score, which is able to provide the overall and objective measure of all domains contributing to each DPI usability. Actually, DPIs can be ranked more effectively in terms of their usability when all the components provided by the GUS Questionnaire are weighted together, such as the subjective and objective components of comparison and ranking.

In other words, the GUS score proved able to limit substantially the role of patient-dependent factors of choice, thus leading to a much more reliable assessment of each DPI usability in real life. These results are emphasized by those of the Bayesian model of comparison that confirmed the ranking of the seven different DPIs provided by the GUS score.

The present investigation has some limitations. The present study is a monocentric survey, even if patients participating were from several Italian regions. Geographical distribution was uneven in patients previously experienced in DPIs use: nonetheless, we believe that this does not represent a relevant confounding factor since the national attitude had never been associated to significant regional differences in DPIs' prescription. Moreover, the original whole sample had to be divided in sub-groups because the GUS Questionnaire consents the comparison of only four devices simultaneously. On the other hand, the simultaneous comparison of more than four DPIs per patient would create severe problems in terms of suitability of their response to the questionnaire. Finally, independently of the strict control of both the quality and duration of the nurses' explanation of each DPI, it was anyway possible that minimal differences would occur in transferring the messages, even if the high predictivity of GUS score tends to exclude the occurrence of substantial biases from this point of view.

However, a point of strength is that, as the study attains to COPD patients, only the seven mostly used DPIs officially indicated as appropriate for COPD management were considered and compared by means of a strict statistical procedure.

\section{Conclusions}

Usability is a multifaceted indicator, which greatly contributes to the definition of DPIs convenience and choice. Usability should not merely mirror the patient's belief (such as, a synonymous of ease-of-use or intuitivity), but it should be regarded as the documented and assessed patient's skill in using inhalation devices effectively, to be measured and/or compared by means of a comprehensive and global score, namely the GUS score. DPIs confirms as characterized by different levels of usability. The GUS score, just because not merely linked to patients' personal at glance and aesthetic beliefs, contributes to the suitable ranking of DPIs in terms of their real-life performance and convenience.

\section{Additional file}

Additional file 1: The Global Usability Score Questionnaire. (DOCX 33 kb)

\section{Abbreviations}

COPD: Chronic Obstructive Pulmonary Disease; Crl: Credibility interval; DPIs: Dry Powder Inhalers; FE: Fixed-effect; GUS: Global Usability Score; IC: Indirect Comparison; RE: Random-effect

\section{Acknowledgements}

None.

Authors' contributions

RWD planned the study, collected data and wrote the manuscript. PT collected data, provided critical feedback and contributed to the final version of the manuscript. MP tested the statistical models, performed the statistical analysis and contributed to the final version of the manuscript. All authors read and approved the final manuscript.

\section{Funding}

No funding was received or previously proposed.

Availability of data and materials

Availability on written request to authors.

Ethics approval and consent to participate

The study was approved by the Ethical and Scientific Commission of the National Centre for Respiratory Pharmacoeconomics and

Pharmacoepidemiology during the session of January 4th, 2016 (\# RD 011/ G01/16). All participants have given their consent.

\section{Consent for publication}

Only data collected from patients who gave their informed consent to the investigation and to the possible use of information for scientific purposes were used for the present study.

\section{Competing interests}

The authors declare no conflict of interest. RWD is Associate Editor of Multidisciplinary Respiratory Medicine.

\section{Author details}

${ }^{1}$ National Centre for Respiratory Pharmacoeconomics and

Pharmacoepidemiology, Verona, Italy. ${ }^{2}$ Research \& Clinical Governance, Verona, Italy. ${ }^{3}$ AdRes Health Economics and Outcome Research, Torino, Italy.

Received: 16 May 2019 Accepted: 7 July 2019

Published online: 13 September 2019

References

1. Virchow JC, Crompton GK, Dal Negro RW, Pedersen S, Magnan A, Seidenberg J, et al. Importance of inhaler devices in the management of airway diseases. Respir Med. 2008;102:10-9.

2. Gustafsson P, Taylor A, Zanen P, Chrystyn H. Can patients use all dry powder inhalers equally well ? Int J Clin Pract Suppl. 2005;149:13-8.

3. Melani AS. Inhalation therapy training: a priority challenge for the physician. Acta Biomed. 2007;78:233-45.

4. Newman SP, Busse WW. Evolution of dry powder inhaler design, formulation, and performance. Respir Med. 2002;96:293-304. 
5. Chapman KR, Fogarty CM, Peckitt C, Lassen C, Jadayel D, Dederichs J, et al. Delivery characteristics and patients' handling of two single-dose dry powder inhalers used in COPD. Int J Chron Obstruct Pulmon Dis. 2011;6: 353-6.

6. Barrons R, Pegram A, Borrens A. Inhaler device selection: special considerations in elderly patients with chronic obstructive pulmonary disease. Am J Health Syst Pharm. 2011;68:1221-32.

7. Chrystyn K. Do patients show the same level of adherence with all powder inhalers? Int J Clin Pract Suppl. 2005;149:19-25.

8. Franks M, Briggs P. Use of a cognitive ergonomics approach to compare usability of a multidose dry powder inhaler and a capsule dry powder inhaler: an open label, randomized, controlled study. Clin Ther. 2004;26: 1791-9.

9. Lenney J, Innes JA, Crompton GK. Inappropriate inhaler use: assessment of use and patient preference of seven inhalation devices. EDICI Respir Med. 2000;94:496-500.

10. Anderson P. Patient preference for and satisfaction with inhaler deviced. Eur Respir Rev. 2005;96:109-16.

11. Perpina Tordera M, Viejo JL, Sanchis J, Badia X, Cobos N, Picado C, et al. Assessment of patient satisfaction and preferences with inhalers in asthma with the FSI-10 questionnaire. Arch Broncopneumol. 2008;44:346-52.

12. Schulte M, Osseiran K, Betz R, Wencker M, Brand P, Meyer T, et al. Handling of and preferences for available dry powder inhaler systems by patients with asthma and COPD. J Aerosol Med Pulm Drug Deliv. 2008;21:321-8.

13. Hodder R, Price D. Patient preferences for inhaler devices in chronic obstructive pulmonary disease: experience with Respimat soft mist inhaler. Int J Chron Obstruct Pulmon Dis. 2009:4:381-90.

14. van der Polen J, Ginko T, Kroker A, van der Valk P, Goosens M, Padullés L, et al. Preference, satisfaction and errors with two dry powder inhalers in patients with COPD. Expert Opin Drug Deliv. 2013;10:1023-31.

15. Hantulik P, Wittig K, Henschel Y, Ochse J, Vahteristo M, Rytila P. Usage and usability of one powder inhaler compared to other inhalers at therapy start: an open, non-interventional observational study in Poland and Germany. Pneumol Alergol Pol. 2015;83:365-77.

16. Kozma CM, Slaton TL, Monz BU, Hodder R, Reese PR. Development and validation of a patient satisfaction and preference questionnaire for inhalation devices. Treat Respir Med. 2005;4:41-52.

17. Rajan SK, Gogtay JA. Ease-of-use, preference, confidence, and satisfaction with Revolizer, a novel dry powder inhaler, in an Indian population. Lung India. 2014;31:366-74.

18. Dal Negro RW, Povero M. Usability and cost-of-usability of three dry-powder inhalers (DPIs) in patients with chronic obstructive pulmonary disease (COPD): may these variables influence the health technology assessment of DPIs? Chron Obstruct Pulm Dis. 2016;1:2-12.

19. Zervas E, Samitas K, Gaga M. Assessment of satisfaction with different dry powder inhalation devices in Greek patients with COPD and asthma: the ANASA study.Int J Chron Obstruct Pulmon Dis. 2016;11:1845-55.

20. Dal Negro RW, Turco P, Povero M. The global usability score: a novel comprehensive tool for assessing, ranking, and compare usability of inhalers in patients requiring airway treatments. J Pulm Respir Med. 2017;7:2. https:// doi.org/10.4172/2161-105X.1000401X.

21. Dias S, Sutton AJ, Ades AE, Welton NJ. Evidence synthesis for decision making 2: a generalized linear modeling framework for pairwise and network meta-analysis of randomized controlled trials. Med Decis Mak. 2013;33:607617. https://doi.org/10.1177/0272989X12458724.

22. NICE Clinical guidelines, no. 92.2010. National Clinical Guideline Centre Acute and chronic conditions (UK). London: Royal College of Physicians (UK). Available at https://www.ncbi.nlm.nih.gov/books/NBK116530/

23. Spiegelhalter DJ, Best NG, Carlin BP, Van der Linde A. Bayesian measures of model complexity and fit. J Royal Stat Soc Series B Stat Methodol. 2002;64 583-639.

24. R Core Team. R. A language and environment for statistical computing. Vienna: R Foundation for Statistical Computing; 2014. http://www.R-project.org/

25. Lunn DJ, Thomas A, Best N, Spiegelhalter D. WinBUGS - a Bayesian modelling framework: concepts, structure, and extensibility. Stat Comput. 2000;10:325-37.

26. Thomas M, Williams AE. Are outcomes the same with all dry powder inhalers? Int J Clin Pract Suppl. 2005;149:33-5 1; 6-7.

27. Brocklebank D, Ram F, Wright J, Barry P, Cates C, Davies L, et al. Comparison of the effectiveness of inhaler devices in asthma and chronic airways disease: a systemic review of the literature. Health Technol Assess. 2001;5:1-149.
28. Kruger P., Ehrlein B, Zier M, Greguletz R. Inspiratory flow resistance of marketed dry powder inhalers. Oral presentation at the European Respiratory Society Annual Meeting, Munich, Germany, september $6^{\text {th }}-10^{\text {th }}$, 2014, proceedings).

29. Lavorini F, Mannini C, Chellini E, Fontana GA. Optimising inhaled pharmacotherapy for elderly patients with chronic obstructive pulmonary disease: the importance of delivery devices. Drugs Ageing. 2016;33(7):461-73.

30. Suarez-Barcelo M, Micca JL, Clackum S, Ferguson GT. Chronic obstructive pulmonary disease in long-term care setting: current practices, challenges, and unmet needs. Curr Opin Pulm Med. 2017;23(suppl 1):s1-s28.

31. Dal Negro RW. Dry powder inhalers and the right things to remember: a concept review. Multidiscip Respir Med. 2015;10(1):13.

32. Price D. Do healthcare professionals think that dry powder inhalers can be used interchangeably? Int J Clin Pract Suppl. 2005;149:26-9.

33. Kubus C, Wick JY. Drug-device combinations: are they appropriate for the ageing population? Consult Pharm. 2016;31:240-50.

34. Rogliani P, Calzetta L, Coppola A, Cavalli F, Ora J, Puxeddu E, et al. Optimiziong drug delivery in COPD: the role of inhaler devices. Respir Med. 2017;124:6-14.

35. Salvi S, Gogtay J, Aggarwal B. Use of breath-actuated inhalers in patients with asthma and COPD an advance in inhalation therapy: a systemic review. Expert Rev Respir Med. 2014:8:89-99.

36. DePietro M, Gilbert I, Millette LA, Riebe M. Inhalation device options for the management of chronic obstructive pulmonary disease. Postgrad Med. 2018;130:83-97.

\section{Publisher's Note}

Springer Nature remains neutral with regard to jurisdictional claims in published maps and institutional affiliations.
Ready to submit your research? Choose BMC and benefit from:

- fast, convenient online submission

- thorough peer review by experienced researchers in your field

- rapid publication on acceptance

- support for research data, including large and complex data types

- gold Open Access which fosters wider collaboration and increased citations

- maximum visibility for your research: over $100 \mathrm{M}$ website views per year

At BMC, research is always in progress.

Learn more biomedcentral.com/submissions 